\title{
NOTA SOBRE AS POLÍTICAS EM PROL DO ENSINO DA HISTÓRIA E CULTURA AFRO-BRASILEIRA E AFRICANA NA EDUCAÇÃO ESCOLAR ${ }^{1}$
}

\author{
Delton Aparecido Felipe ${ }^{2}$ \\ Teresa Kazuko Teruya \\ Universidade Estadual de Maringá - UEM
}

\section{RESUMO}

A aprovação da Lei 10.639 em 9 de Janeiro de 2003 que estabelece a obrigatoriedade do ensino da história e cultura afro-brasileira e africana na educação básica suscitou um série de debates sobre a relevância de políticas educacionais como a pautada nesta Lei. A fim de contribuir como esse debate, o presente artigo tem como objetivo analisar a relevância da aprovação da Lei 10.639/2003 na educação escolar brasileira, na perspectiva dos Estudos Culturais. Para isso estabelecemos como questão norteadora de nosso artigo: quais as implicações pedagógicas a Lei 10.639/2003 terá na educação escolar? Apresentamos as mudanças ocorridas na educação escolar, dando ênfase à disciplina de História, já que é uma das disciplinas que tem em seu currículo diversas questões sobre as relações étnico-raciais. Concluímos que a aprovação de Leis como a citada contribui para ampliar o conhecimento dos docentes sobre sua prática pedagógica enquanto formadores de posicionamentos sociais. A Lei abre caminho para a construção de uma educação antirracista e rompe com as normas discursivas centradas no europeu. A Lei permite que no ambiente escolar, seja legítimo falar sobre a exclusão e marginalização de um segmento social.

Palavras-chave: Educação escolar, formação de professores e professoras, Políticas educacionais e história e cultura afro-brasileira.

\section{NOTE ON POLICIES IN SUPPORT OF THE TEACHING OF HISTORY AND AFRO-BRAZILIAN CULTURE AND AFRICAN SCHOOL OF EDUCATION}

\begin{abstract}
The approval of Law 10,639 on 9 January 2003 establishing the mandatory teaching of history and culture african-Brazilian and African basic education led to a series of debates about the relevance of educational policies as guided by this law in order to contribute as this debate, this article aims to analyze the relevance of the adoption of the Law 10639/2003 in Brazilian school education from the perspective of Cultural Studies. To have established guiding question of our article: What are the educational implications of the Act will 10639/2003 school education? Present the changes in education, emphasizing the discipline of history, since it is one of the disciplines that has done a number of questions about the ethnic-racial relations. We conclude that the adoption of laws like the one contributes to the knowledge of teachers on their teaching practice as trainers of social positions. The law paves the way for the construction of an education "antirracista" and breaks with the standards discourse centered on Europe. The law makes room for that in the school environment, it is legitimate to talk about the exclusion and marginalization of a segment of society.

Keywords: school education, teacher training and teachers, educational policies and history and afro-brasilian culture
\end{abstract}




\section{Introdução}

O objetivo deste artigo é analisar a relevância do debate sobre o ensino de história e cultura afro-brasileira e africana na educação escolar no Brasil no campo das políticas. Nadai (1992) afirma que no final da década de 70 do século XX passou-se questionar os conceitos elaborados para a sociedade brasileira, como o conceito de democracia racial e o de cidadania. Com isso, enveredou-se pelo caminho do debate político sobre o significado do ensino de história no contexto de uma sociedade que estava lutando para se redemocratizar.

Nesse período, houve um forte processo de rejeição ao ensino de história, recomendado pelos governantes brasileiros para forjar o espírito de nacionalidade. Questionava-se o ensino preocupado em reproduzir uma narrativa histórica que servia ao propósito da construção da identidade nacional e da manutenção de determinado grupo no poder. Ficava evidente, nessas discussões, que a concepção de ensino nascente estava comprometida com as transformações sociais almejadas pelos movimentos sociais emergentes. Neste sentido, as propostas para o ensino de história desafiavam as condições políticas para reverter a equação do poder, até então, representativo da nação brasileira e, a partir dessa reversão, implementar um projeto social mais justo, mais humano e com a participação efetiva de todos os grupos sociais.

Os debates sobre quais conteúdos ensinar e como ensinar, promovidos na década de 1980, contribuíram para o início da reformulação de concepções teóricas e metodológicas da disciplina de História, exigindo que os conteúdos a serem oferecidos na educação formal levassem em consideração as reivindicações dos grupos sociais. Schmidt e Cainelli (2004) entendem que o grande marco de reformulações desse ensino concentrou-se na perspectiva de tratar docentes e discentes como sujeitos da história e da produção do conhecimento histórico, com o objetivo de formar sujeitos produtores da história, não mais receptores passivos, espectadores de uma história de heróis que compunha os personagens dos livros didáticos.

De maneira geral, as discussões sobre a constituição do saber histórico, que se desenvolveram no final da década de 1970 e na década de 1980, foram inspiradas nos referenciais teóricos, metodológicos e temáticos produzidos especialmente na França, Inglaterra, Itália e nos Estados Unidos. Nadai (1992) argumenta que outros sujeitos sociais, de maneira progressiva, foram incorporados nos estudos historiográficos. A partir 1980, por exemplo, as mulheres, os negros, os homossexuais, os prisioneiros, os loucos e as crianças, sujeitos que, até esse período constituíam uma ampla população de excluídos, reclamavam seu lugar na história social do país.

As reformulações curriculares passaram a ser permeadas por discussões que questionavam os conteúdos ensinados na educação escolar em todos os níveis. Aqueles pertencentes às culturas negadas e silenciadas nos currículos escolares começavam a reagir contra a sua marginalização. De acordo com Gomes (2008), os excluídos dos discursos normativos do currículo escolar lançaram mão de estratégias coletivas e individuais, articulando-se em redes, dando início a diversos movimentos sociais de caráter identitário.

A mobilização das culturas negadas atinge as escolas, as universidades e a produção do conhecimento. Na disciplina de História, organizam-se vertentes que reivindicam uma perspectiva da história de todos os homens e não somente dos heróis. De acordo com essas vertentes, e entre elas a Nova História Cultural, não era mais possível aceitar as narrativas com ênfase exclusiva na visão européia. Schmidt e Caineli (2004) argumentam que esse processo atingiu os currículos, os sujeitos e suas práticas, instalando um processo de renovação que, nesse período, ficou restrito mais à teoria do que sua efetivação na prática. 
Dentre os movimentos sociais que lutavam pela representatividade nas esferas sociais brasileiras, encontra-se o Movimento Negro Unificado (MNU). De acordo com Pereira (2002), tal movimento iniciou-se em São Paulo na década de 1970, em pleno regime militar, com o objetivo de combater o mito da democracia racial e denunciar que o Brasil é uma nação racista, na qual os negros estavam subrepresentados na maioria das instituições sociais. Além disso, o papel do MNU era fomentar um processo de constituição da identidade positiva do negro e de sua conscientização política na vida nacional. Paul Singer, um dos fundadores do MNU, em carta aberta, lida em ato público no dia 7 de julho de 1978 nas escadarias do Teatro Municipal de São Paulo, posicionava-se contra a discriminação no Brasil:

\begin{abstract}
Não podemos mais calar. A discriminação racial é um fato na sociedade brasileira, que barra o desenvolvimento negro, destrói a sua alma e sua capacidade de realização como ser humano [...]. Não podemos mais aceitar as condições em que vive o homem negro sendo discriminado da vida social do país, vivendo no desemprego, subemprego e nas favelas. Não podemos mais consentir que o negro sofra perseguições constantes da polícia sem dar uma reposta. (SINGER, 1981, apud SILVA, 2001, p. 38)
\end{abstract}

A manifestação do MNU teve dois propósitos: o primeiro, como um movimento de denúncia do racismo existente no Brasil. A elite brasileira tentava constituir, no Brasil, a ideia de que todos eram tratados como iguais independentes da cor pele. Essa ideia apoiavase nas publicações das obras de Gilberto Freire, Casa Grande \& Senzala de 1932, e de Sérgio Buarque de Holanda, Raízes do Brasil, de 1947, nas quais afirmavam que, apesar da escravidão que houve no Brasil, não se sobressaiu o racismo, visto que o negro, o índio e o branco se misturam amigavelmente. Segundo, como processo de formação da identidade positiva do negro, por meio de ações políticas, com a valorização de seus aspectos simbólicos, formas de vestir, de pentear e de falar. O bloco afro Ilê Aiyê, um dos primeiros blocos de carnaval representativo da cultura afro-brasileira, captou esse sentimento dos ativistas das organizações negras, fazendo o seguinte registro:

Durante este tempo demos o nosso grito de liberdade [...] A liberdade de podermos ser negros, de dançar a nossa dança, de cantar o nosso canto. Canto esse que conta a nossa história e nossa libertação. E esse verdadeiro canto ecoou no Curuzu: um canto de fé por um mundo melhor. O brilho da avenida não ofusca o brilho desta raça de origem nagô (CADERNOS CANTO..., 1988, p. 32)

Percebemos, nesse registro, que os ativistas acreditavam no reconhecimento e na recriação dos aspectos da cultura negra. Representados socialmente, eles ampliam os argumentos para a ação política de combate ao racismo. Silva (2001) lembra que a afirmação de traços distintivos culturais e físicos da população negra, além de servir como resposta imediata às posturas racistas, indica que as identidades individuais ou coletivas não podem ser interpretadas como avesso à identidade social.

Após três décadas de reivindicações do MNU, verificamos que houve avanços na luta contra o racismo e a discriminação da população negra no Brasil, mas, ainda, o racismo e o preconceito persistem na sociedade brasileira. Hoje, não é mais aceitável a ideia de democracia racial entre os brasileiros. Com a promulgação da Constituição de 1988, considerada por muitos uma constituição cidadã, houve uma tentativa de valorização dos diversos povos e culturas existentes no Brasil, por exemplo: o $5^{\circ}$ artigo, no parágrafo XLII, 
prevê que casos de discriminação racial serão tratados como crimes imprescritíveis e inafiançáveis. Este artigo reconhece a existência do racismo no Brasil.

Não podemos só reconhecer a existência do racismo no Brasil, é necessário combatêlo e trabalhar para amenizar as conseqüências da submissão e da marginalização do negro brasileiro. Nesse ponto, ainda encontramos grandes dificuldades. Uma das primeiras instituições sociais chamada a entrar na luta contra o racismo e para a valorização da população negra em seus aspectos físicos e culturais como formadoras da população brasileira foi à escola. Há uma crença de que a escola, em cada momento histórico, constitui-se uma expressão e uma resposta à sociedade. Ela reflete uma porta de entrada para a construção de um Brasil onde convivem as diversas influências que caracterizam a formação do nosso povo.

\section{A diversidade étnico-racial: educação escolar e ensino de História no Brasil}

No Relatório das Diretrizes Curriculares Nacionais para a Educação das Relações Étnico-Raciais Para o Ensino de História e Cultura Afro-brasileira e Africana, a professora Beatriz Petronilha Gonçalves e Silva (BRASIL, 2004) defende que as instituições de ensino no seu papel de educar, devem abrir um espaço democrático de produção e divulgação de conhecimentos e de posturas que visam uma sociedade justa.

Ao estudar as origens da educação escolar pública brasileira, no final do século XIX, verificamos que os negros não foram alvos das instituições de ensino, já que a escolarização visava formar o ideal de homem brasileiro que tinha como referência o homem branco europeu. Quando analisamos o pensamento educacional brasileiro depois da abolição da escravidão, o negro e sua cultura foram silenciados no currículo escolar. (FELIPE; TERUYA, 2007).

Durante um século de funcionamento da escola pública, a história do negro e cultura africana $^{3}$ foi abordada de forma distorcida e estereotipada nos conteúdos curriculares da educação básica. Somente na década de 1980, com as constantes reivindicações do Movimento Negro Unificado, houve tentativas de inserir conceito de pluralidade na educação brasileira. No entanto, o debate sobre educação e diversidade se intensifica só depois de 1990, com a tramitação das leis voltadas para a educação nacional.

Os debates promovidos depois de 1980 sobre a pluralidade cultural do Brasil favoreceram várias modificações importantes na educação escolar e no ensino de História no Brasil. Apesar da renovação teórico-metodológica da história nos últimos anos, Fernandes (2005) reconhece que o conteúdo programático dessa disciplina na educação básica ainda tem primado por uma visão monocultural e eurocêntrica de nosso passado. Isso significa que a educação escolar ainda não aprendeu a valorizar a diversidade étnico-racial que compõe o espaço escolar.

O termo diversidade é empregado aqui no sentido utilizado por Abramowicz (2006, p.12) que "[...] pode significar variedade, diferença e multiplicidade. A diferença é qualidade do que é diferente; o que distingue uma coisa de outra, a falta de igualdade ou de semelhança". A educação para a diversidade supõe levar em consideração os aspectos culturais dos mais diferentes grupos, permitindo que eles expressem a si próprio na busca da aprendizagem e do conhecimento.

Também entendemos os conceitos de raça e etnia como construções sociais, forjadas nas relações entre cultura, conhecimento e poder. $\mathrm{O}$ conceito de raça, utilizado dentro de uma perspectiva política, nada tem a ver com conceito biológico de raça cunhado no século XIX. No contexto de questionamento de uma cultura homogênea, Silva, no Relatório sobre a Lei 10.639/2003 (BRASIL, 2004), afirma que o termo raça é utilizado para informar como 
determinadas características físicas, como cor da pele, tipo de cabelo, entre outras, influenciam, interferem e até mesmo determinam o destino e o lugar social dos sujeitos no interior da sociedade brasileira.

O emprego do termo étnico, na expressão étnico-racial, como faz Silva (BRASIL, 2004), serve para marcar que as relações tensas causadas pelas diferenças na cor da pele e traços fisionômicos são também por causa da raiz cultural plantada na ancestralidade africana, que pode diferir em visão de mundo, valores e princípios das origens indígena, européia ou asiática.

Em um resgate da história do negro no Brasil, é importante ressaltar que os africanos negros aportados em nosso território na condição de escravizados, são vistos como mercadoria e objeto nas mãos de seus proprietários. Foi atribuída ao negro uma participação subalterna na construção da história e da cultura brasileira, embora tenha sido ele a mão-deobra predominante na produção da riqueza nacional, trabalhando na cultura canavieira, na extração aurífera, no desenvolvimento da pecuária e no cultivo do café em diferentes momentos de nosso processo histórico. Quando se trata de abordar a cultura dessas minorias, estamos pensando no sentido político da palavra, já que os dados do IBGE demonstram que a população negra brasileira é de 47,2\% (BRASIL, 2007), mas ela é vista de forma folclorizada e pitoresca e as culturas européias elevadas à condição de superiores e civilizadas.

O ensino de história do Brasil ainda está permeado pela concepção da historiografia brasileira que prima pelo relato dos grandes fatos e feitos dos chamados heróis nacionais, geralmente brancos, escamoteando, assim, a participação de outros segmentos sociais no processo histórico do país. Para Silva (1998), a maioria das concepções históricas que perpassa o ensino de história no Brasil despreza a participação das minorias étnicas, especialmente de índios e negros. Quando eles aparecem nos livros didáticos, seja em forma de textos, seja em forma de ilustrações, são tratados de forma pejorativa e, portanto, preconceituosa e estereotipada.

Os currículos e os manuais didáticos usados na educação básica insistem em silenciar e até mesmo chegam a omitir a condição de sujeito histórico e de portador de práticas culturais das populações negras e ameríndias.

Além da encucação ideológica promovida pelo cinema, rádio, TV, revistas e instituições, o livro didático, pela importância que lhe é atribuída pelo poder do Estado de transmitir "Verdades" que lhe é conferido, consegue de forma sistemática inculcar na cabeça dos jovens e crianças conceitos e visões deformadas e cristalizadas, que passam a ser assumidas como conceitos e visões da "realidade" que se constitui ideologicamente. (SILVA, 1998, p. 03).

É fato incontestável que somos uma nação com múltiplas culturas, em virtude de nossa formação histórica, porém o que se percebe é que a população brasileira não aprendeu a conviver com a diversidade étnico-racial. E a educação escolar ainda persiste em ministrar os seus conteúdos pautados em seu imaginário étnico-racial, um país que privilegia a brancura e valoriza, sobretudo, as raízes européias da sua cultura, ignorando ou pouco valorizando as outras. Por exemplo, a história da África, no currículo escolar, é vista como uma paisagem exótica e totalmente desvinculada da história brasileira, atrelada a uma imagem de que o africano é um semi-selvagem, acorrentado em sua miséria.

A fim de combater essa visão monocultural e eurocêntrica que foi forjada no saber histórico brasileiro, ao ter como padrão a visão dos grupos dominantes, o governo brasileiro, por meio de seus órgãos legais, tem incorporado na legislação brasileira alguns tópicos de 
modo a contribuir com a visualização de um Brasil pluriétnico. A Lei de Diretrizes e Bases da Educação Nacional (LDB), em seu artigo 26, parágrafo 4, ratificando posição da Constituição Federal de 1988, determina que "[...] o ensino história do Brasil levará em conta as contribuições das diferentes etnias para a formação do povo brasileiro, especialmente das matrizes indígena, africana e européia" (BRASIL, 1996a)

Por sua vez, o Ministério da Educação (MEC), em cumprimento ao dispositivo constitucional assente no art. 210 de nossa Carta Magna e sensível à necessidade de uma mudança curricular face à emergência de temas sociais relevantes para a compreensão da sociedade contemporânea, elaborou para a educação básica os Parâmetros Curriculares Nacionais (PCN). A grande inovação dessa proposta é a existência de temas transversais que deverão perpassar as diferentes disciplinas curriculares - Língua Portuguesa, Matemática, História, Geografia, Ciências e Artes - e permitir, com isso, a interdisciplinaridade no ensino fundamental, tais como: Convívio Social e Ético, Pluralidade Cultural, Meio Ambiente, Orientação Sexual, Saúde, Trabalho e Consumo.

Após as discussões com as secretarias de educação de estados e municípios e com especialistas de diversas áreas do conhecimento, os PCN foram aprovados pela Câmara de Educação Básica do Conselho Nacional de Educação (CNE), servindo de referência nacional para que os sistemas de ensino estaduais e municipais pudessem adequá-lo à sua realidade educacional (BRASIL, 1997).

Reconhecendo a necessidade de uma educação multicultural, os PCN estabelecem como tema transversal o estudo da Pluralidade Cultural, a fim de ser trabalhada em diferentes disciplinas curriculares.

[...] temática da Pluralidade Cultural diz respeito ao conhecimento e à valorização das características étnicas e culturais dos diferentes grupos sociais que convivem no território nacional, às desigualdades socioeconômicas e à crítica às relações sociais discriminatórias e excludentes que permeiam a sociedade brasileira, oferecendo ao aluno a possibilidade de conhecer o Brasil como um país complexo, multifacetado e algumas vezes paradoxal. (BRASIL, 1997, p. 33).

Esse mesmo documento do MEC traz como um dos objetivos gerais da educação básica o conhecimento e a valorização da pluralidade do patrimônio sociocultural do país, bem como aspectos socioculturais de outros povos e nações, devendo alunos e alunas, professores e professoras posicionarem-se contra quaisquer formas de discriminação baseada em diferenças culturais, de classe social, de sexo, de etnia ou outras características individuais e sociais.

Além dos PCN, dispomos das diretrizes curriculares elaboradas pelo CNE para a educação básica. Recentemente, esse órgão normativo e consultivo do MEC instituiu, com base no parecer da conselheira Petronilha Beatriz Gonçalves e Silva, as Diretrizes Curriculares Nacionais para a Educação das Relações Étnico-Raciais e para o Ensino de História e Cultura Afro-brasileira e Africana.

Ainda no âmbito das políticas públicas governamentais, podemos citar o Programa Nacional de Direitos Humanos, elaborado pelo Ministério da Justiça na gestão do Presidente Fernando Henrique Cardoso, que previa, entre uma série de ações para as populações negras no Brasil, o estímulo à "[...] elaboração de livros didáticos que enfatizem a história e as lutas do povo negro na construção do nosso País, eliminando estereótipos e discriminações" (BRASIL, 1996b, p. 31).

Mais recentemente, por ocasião do início do Governo Lula, foi sancionada a Lei $n^{\circ}$. 10.639, de 9 de janeiro de 2003, que “[...] altera a Lei no. 9.394, de 20 de dezembro de 1996, 
que estabelece as diretrizes e bases da educação nacional, para incluir no currículo oficial da rede de ensino obrigatoriedade da temática História e Cultura Afro-Brasileira, e dá outras providências". A Lei estabelece o estudo da história da África e dos africanos, a luta dos negros no Brasil, a cultura negra brasileira e o negro na formação da sociedade nacional, resgatando a contribuição do povo negro nas áreas sociais, econômicas e políticas pertinentes à História do Brasil (art. 26-A, $\S 1^{\circ}$ ) e, tornando-o obrigatório no currículo escolar da educação básica (BRASIL, 2003).

Neste momento histórico, a demanda por geração de oportunidades requer do Estado e da sociedade medidas que contemplem a população negra nas oportunidades que irão amenizar os danos psicológicos, materiais, sociais, políticos e educacionais herdados do regime escravista, bem como das políticas explícitas ou tácitas de branqueamento da população, de manutenção de privilégios exclusivos para os grupos com poder de governar e de influir na formulação das políticas no pós-abolição. Tais medidas se concretizam com iniciativas de combate ao racismo e demais formas de discriminação.

O posicionamento daqueles que já conhecem este dispositivo legal é dividido, uns concordam e outros discordam. Os argumentos da discordância sustentam que a Lei não se traduz, na prática, em uma mudança necessária e que produziria um acirramento ainda maior entre os vários grupos étnicos que compõem a população brasileira. Alem disso, argumentam os discordantes que a legislação seria racista por privilegiar um setor especifico do mosaico étnico brasileiro em detrimento dos demais. Um exemplo desse pensamento é do professor Peter Fry (2005) que, em seu livro A Persistência da Raça afirma que a Lei 10.639/2003 estaria reapresentando o surrado conceito de raças humanas, portanto, não possui base científica pelo simples motivo que existe apenas uma raça: a humana. Nesse sentido, Fry afirma que a Lei 10.639 poderia desencadear reações de outros grupos, constrangidos por estarem pouco representados nos currículos.

Os argumentos dos concordantes postulam que a Lei é fundamental, porque contribui para ampliar o conhecimento sobre a história dos negros formadores da população brasileira. Para Lopes (2003, p. 19), “[...] a Lei 10.639/2003 do CNE vem reconhecer a existência do afro-brasileiro e seus ancestrais (os africanos), sua trajetória na vida brasileira e na condição de sujeitos que contribuíram para a construção da sociedade". Acrescenta que é preciso ser inserida no currículo escolar para modificar os conteúdos hegemônicos de cunho eurocêntrico contidos no sistema escolar, e obter um resultado desejável de respeito às diferentes culturas no processo de ensino e de aprendizagem. Essa alteração, em seus aspectos explícitos e implícitos, precisa ser construída no cotidiano do fazer pedagógico no interior das escolas, envolvendo alunos, professores, corpo diretivo, corpo administrativo e comunidade escolar em geral, tendo como suporte um currículo com base na abordagem da diversidade cultural.

Outro argumento favorável é que, apesar de a Lei de Diretrizes e Base da Educação Nacional (LDB, 9394) aprovada em 1996, ter explicitamente incluído a história afrobrasileira como conteúdo pedagógico, na realidade, nada disso aconteceu. Nessa concepção, a nova Lei estaria antes de tudo cobrando efetivação de um parecer pedagógico já existente.

Em nossa perspectiva, os argumentos dos que afirmam que a Lei 10.639/2003 estaria privilegiando uma etnia determinada, a dos negros, não se sustenta. No Brasil, o grupo afrodescendente negro, mesmo constituindo cerca de 50\% da demografia brasileira, ainda está sub-representado na maioria das esferas da vida social. Essa ausência de representatividade repercute no sistema de ensino, que desqualifica ou simplesmente se cala a respeito da história e da cultura negro-africana.

Quanto aos demais grupos, segundo Serrano e Waldman (2007), é possível argumentar que a própria lei que incentiva o ensino da história e cultura afro-brasileira e 
africana também inclui a discussão sobre a diversidade étnico-racial no Brasil. Estas medidas contribuem para a reeducação das relações entre os vários grupos sociais constituintes da sociedade brasileira, provocando o questionamento das relações étnicoraciais baseadas em preconceitos e na desqualificação do outro. Tal argumento pode ser comprovado com a aprovação em março de 2008 da Lei 11.645 que, além da obrigatoriedade do ensino da história e cultura afro-brasileira e africana na educação básica, prevê também o ensino da história e cultura indígena (BRASIL, 2008).

Por fim, em relação aos segmentos que repudiam a Lei em nome de um suposto racismo que estaria perpassando a sua essência ao prever o ensino da história e da cultura afro-brasileira, entendemos que a questão racial não se esgota em um ponto de vista genético, é necessário ressaltar os condicionamentos histórico-sociais dos conceitos que envolvem as questões raciais. Se, no passado, a ideia da existência de raça superior e da raça inferior legitimava a escravização com comprovação científica da inferioridade dos negros, atualmente, para legitimar a ordem estabelecida, funda-se na não existência de raças, apoiando-se nos direitos democráticos válidos para todas as etnias. A existência ou não de raça depende da conveniência em um determinado momento social.

A Lei 10.639/2003 constitui um passo importante para resgatar e valorizar os diversos grupos étnicos que estão à margem da sociedade brasileira. Os currículos escolares do sistema educacional podem ser aliados valiosos nessa luta, como ressalta Gomes (2008), esta Lei que não é somente uma norma: é resultado da ação política e da luta de um povo cuja história, sujeitos e protagonistas ainda são poucos conhecidos.

$\mathrm{Na}$ educação escolar, verificamos uma dificuldade em ensinar e aprender história, trabalhar o real e o imaginário. O principal problema, quando se trata do ensino de história e cultura afro-brasileira e africana, não se encontra em sua complexidade, mas sim nas informações disponibilizadas, especialmente na mídia, que são distorcidas e não condizem com a realidade.

\section{Aplicação da lei 10.639/20003 na sala de aula}

Sem dúvida, a Lei representa um avanço ao possibilitar a construção de um multiculturalismo crítico na escola brasileira, ao mesmo tempo em que se reconhece uma luta histórica do movimento negro em nosso país, cuja bandeira de luta consiste em incluir no currículo escolar o estudo da história e cultura afro-brasileira. Por outro lado, não podemos nos esquecer que ainda precisamos de muitas ações para que a Lei não se torne letra-morta e contribua, de fato, para uma educação multicultural com o questionamento das relações sociais desiguais.

Lopes (2003), utilizando os estudos de Sacristán, assinala que o termo multicultural é ambíguo e enganador, por se tratar de um rótulo em que cabem várias perspectivas. Ela explica que tanto pode se referir a uma perspectiva assimilacionista, em que uma cultura dominante objetiva assimilar uma cultura minoritária em condições desiguais e com oportunidades menores no sistema educacional e social, como pode ser multiétnica, um instrumento para diminuir preconceitos de uma sociedade para com as minorias étnicas, ou ainda associada a um pluralismo cultural, em que se busca proporcionar visões plurais da sociedade e de suas elaborações.

Mas, ainda de acordo com a autora, apesar de tal discurso, não se pode deixar de identificar o pluralismo cultural com a aceitação do diferente, e essa concepção pode ser vista sob dois enfoques: o do consenso e o do conflito. $\mathrm{O}$ do conflito seria aquele que exigiria processos argumentativos e embates sociais para sua resolução e o do consenso objetivaria superar os conflitos sem confrontação. 
Para trabalhar a história da África em sala de aula, como nos alerta Conceição (1999), temos que levar em consideração algumas questões: como pensar uma escola que tenha por base uma educação na perspectiva da pluralidade étnico-racial? Como romper com o modelo pedagógico vigente? O que fazer para que a sociedade civil, organizada por meio de suas legítimas representações, inclua o afro-brasileiro? Estas questões são fundamentais para contemplar os brasileiros descendentes de africanos, para pensar em uma nova educação escolar. Neste sentido, consideramos necessário efetivar algumas ações no processo educativo de sala de aula, especialmente formar um novo perfil de professor e professora e de aluno e aluna que, no exercício da reflexão sobre o seu "eu" e o "outro", apropriem-se dos saberes sobre a história e a cultura afro-brasileira e africana para serem socializados com as respectivas comunidades, a fim de romper com a pedagogia que prioriza o modelo eurocêntrico.

Fernandes (2005) afirma que um dos gargalos do sistema educacional brasileiro reside na qualificação do corpo docente, sobretudo os que exercem o magistério nas séries iniciais do ensino fundamental. Esses professores e professoras, em sua maioria, recebem uma formação polivalente e, portanto, precisam de qualificação para trabalhar com essa nova temática curricular. $\mathrm{O}$ autor sugere, para tanto, um esforço por parte dos órgãos governamentais ligados à área de promoção da igualdade racial para oferecer, em parceria com as instâncias educacionais, cursos de extensão sobre a história da África e de cultura afro-brasileira, bem como a publicação de material didático-pedagógico que possa dar suporte técnico à atuação desses docentes no processo de ensino e aprendizagem

Dessa forma, para tratar a temática do negro no currículo escolar, não é necessário que o professor e a professora sejam negros. A lei tem um caráter obrigatório para todo o magistério e com a função estratégica para a formação do cidadão brasileiro. Para cumprir a lei, os conhecimentos relativos a essa temática devem ser socializados entre os demais educadores e educadoras e ampliados para toda comunidade escolar. Com isso, o "[...] professor e a escola não serão mais acusados de serem mediadores - mesmo que inconsciente - da formação de estereótipos que geram preconceitos que se constituem de um juízo prévio a uma ausência de um real conhecimento do outro" (SILVA, 2001, p. 73).

Cunha Júnior (1998) enfatiza que o racismo, o preconceito e a discriminação são os malefícios que existem tanto na escola quanto na sociedade em geral, muitas vezes mascarados e naturalizados ou, ainda, assumidos explicitamente nas atitudes, nos valores e nas normas vigentes, presentes em nosso cotidiano. São manifestações de um processo cruel de dominação, que mina a cultura dos grupos sociais considerados dominados entre nós, os negros e os indígenas.

Silva (2001) alerta que trabalhar a partir de valores eurocêntricos no sistema escolar leva as crianças e adolescentes negros a se sentirem inferiores e a serem considerados como tal pelos demais. A convivência com a imagem estereotipada, que causa danos psicológicos e morais, pode bloquear a personalidade étnica e cultural do afro-descendente.

Felipe e Teruya (2008) afirmam que o brasileiro, de um modo geral, sabe pouco a respeito dos afro-descendentes, e, quando sabe, seu conhecimento está repleto de ideias preconceituosas. Trata-se de um conhecimento sincrético. Começa com a entrada do negro no Brasil como mercadoria. A imagem do negro descalço, seminu e selvagem é mostrada na literatura escrita por brancos, sem contar a história do africano livre, dono de sua própria vida e produtor de sua própria cultura. Ao falar dos aspectos da cultura africana e da história do negro no Brasil, entramos em um campo de tensões e de relações de poder que nos leva a questionar as representações e os estereótipos sobre a África, os africanos, negros brasileiros e sua cultura. A ideia de inferioridade cultural dos negros, construída historicamente e socialmente, justificou os processos de dominação, colonização e escravização. 
No ensino de história e cultura afro-brasileira e africana não se trata de mudar o foco etnocêntrico marcadamente de raiz europeu pela africana, mas de ampliar o foco dos currículos escolares para a diversidade cultural, racial e social e econômica brasileira. Cabe às escolas incluírem os estudos e as atividades que proporcionam contribuições históricoculturais dos povos indígenas e dos descendentes de asiáticos e além destas, das raízes africanas e européias.

As reivindicações estabelecidas na Lei 10.639/2003 lançam novas bases para o ensino de história, uma vez que o legado eurocêntrico resultou em um raciocínio que ainda hoje dificulta os estudos sobre África e sobre negro no Brasil, constituindo um sério obstáculo para a compreensão da realidade histórica do continente africano e de seus descendentes.

\section{Novas bases para o ensino de História da África na educação escolar: desconstruindo mitos}

O conhecimento de um determinado tema, na nossa perspectiva, é construto social, para promover a releitura da história africana eivada de preconceitos, é necessário questionar vários conceitos solidificados no decorrer da história, é necessário desconstruir as estereotipias que foram forjadas pelo imaginário europeu sobre África e seus descendentes. Como nos alerta Meneses (2007, p. 56), “[...] falar sobre a África significa questionar e desafiar crenças adquiridas, pressupostos afirmados e múltiplas sensibilidades".

Quando nos reportamos ao termo desconstruir, referimo-nos aos procedimentos da análise do discurso nos moldes adotados pelo filósofo Jacques Derrida, que pretendem mostrar as operações, os processos que estão implicados na formulação de narrativas tomadas como verdades, em geral, tidas como universais e inquestionáveis. A desconstrução tem possibilitado vislumbrar com nitidez as relações entre os discursos e o poder. "Ao contrário do que muitas pessoas pensam desconstruir não significa destruir. Desconstruir, neste caso, significa uma estratégia de demonstrar para poder mostrar as etapas seguidas na montagem". (COSTA, 2002, p. 140).

Compreender e contextualizar as informações sobre aspectos do continente africano é, indiscutivelmente, um exercício critico. Serrano e Waldman (2007) argumentam que existem visões estereotipadas cultivadas contra os povos africanos e suas regiões. Mais do que qualquer outro continente, a África terminou encoberta por um véu de preconceitos, que, ainda hoje, marcam a percepção de sua realidade.

O imaginário europeu devotou para as terras africanas e para os seus habitantes um amplo leque de injunções desqualificantes, muitas vezes respaldadas pelos intelectuais europeus. A África foi condenada ao papel de espaço periférico da humanidade, além de desprovida de adjetivos que engrandecem na visão dos europeus.

$\mathrm{Na}$ realidade, os mecanismos simbólicos da exclusão do outro remontam de muitos séculos, estando profundamente enraizados no legado cultural europeu. Serrano e Waldman (2007) revelam que o discurso europeu a respeito da África é antigo, pode ser localizado um variado conjunto de elaborações socioculturais. É a partir desse passado remoto que se estratificou o preconceito cultivado contra o outro, personificado em diferentes momentos pelos bárbaros, tártaros, mongóis, ciganos, judeus, muçulmanos, assim como pelos negros africanos.

É inegável que o mundo ocidental construiu o seu relacionamento com as populações extraeuropéias com base em preconceitos de todo tipo. Nesse particular, Cunha Júnior (1998) afirma que o continente africano foi, inegavelmente, o mais desqualificado pelo pensamento europeu. Ainda que a imagem da África tenha variado ao longo do tempo em decorrência de diferentes formas de relacionamento estabelecidas com os seus povos, é 
indiscutível que este continente foi mais que qualquer outro, naturalizado pelo pensamento ocidental com imagens negativas e excludentes.

O embrião dessas concepções discriminatórias remete às formulações surgidas na antiguidade clássica. Para os antigos gregos e romanos, a África compreendia as terras situadas entre os países atuais Líbia e Marrocos, habitados por povos de idioma berbere (o termo não designa nenhuma etnia, diz respeito a um grupo de línguas que integra a família afro-asiática). Desse modo, refere-se a povos cujas características são, em alguns contextos, muito discrepantes entre si. Seria o caso dos garamantes, númidas, líbios e mauritânios, costumeiramente mencionados nas crônicas e documentos do Império Romano. Recorda-se que o termo berbere deu origem à palavra, bárbaro, para identificar as populações cuja língua e cultura eram consideradas inferiores em relação às greco-romanas, consideradas como padrão hegemônico. (SERRANO; WALDMAN, 2007).

Historicamente, o regime de estereotipias imposto à África foi reforçado pela distância e relativo isolamento do continente em relação ao resto do mundo europeu. A África, em particular a África negra ou Subsaariana, constituía um domínio nebuloso, por causa das informações fragmentárias e distorcidas. As imagens do continente africano, construídas pelo imaginário medieval, suscitavam todo o tipo de objeções. Assolados pelo calor inclemente, os territórios meridionais estariam infestados de monstros e outros seres fabulosos, coabitando com grupos de semi-humanos ou de humanos inferiores. Decididamente, o quadro construído pelo imaginário social europeu relacionado à África foi contemplado com estigma da subalternidade. Não é de admirar que as representações confirmem uma pretensa inferioridade.

$\mathrm{Na}$ modernidade, o rebaixamento da África relaciona-se intimamente às demandas da sociedade capitalista ocidental, que, de modo contínuo, reapresenta para o continente a condição periférica do sistema de produção de mercadorias. Desse modo, se, no período do mercantilismo, foi reservado à África o papel subalterno de fornecer mão-de-obra compulsória para a monocultura açucareira e para a extração de metais e pedras preciosas, com a hegemonia do capitalismo industrial, o continente é novamente subalternizado, enquadrado na condição de manancial de mão-de-obra barata e de fornecedor de matérias primas para as potências industriais. Nesse sentido, a necessidade de justificar o domínio europeu induziu e foi mantida mediante o desenvolvimento de teorização que, apelando para as distorções conceituais, desqualificava o legado africano em todos os sentidos.

Se, no período mercantilista, a África reunia características espirituais, religiosas e elementos fabulosos inscritos no seu espaço geográficos, na fase do capitalismo industrial, é a carência de civilização o principal argumento para sua estereotipia. Nessa perspectiva, o continente africano passa ser visto como, de fato, deveria ser entendido: um continente simplesmente carente de civilização.

Mais uma vez, a África foi alvo da política de hierarquização do conhecimento imposto pelas expectativas do mundo europeu e, agora, a constituição do discurso desclassificatório voltado a África é de que ela não era civilizada, cabendo ao europeu levar a civilização ao continente africano. A África foi inteiramente retalhada e distribuída entre as potências coloniais, que reorganizaram o espaço africano aos seus interesses, ignorando todo e qualquer arranjo espacial anterior. Segundo Serrano e Waldman (2007) com exceção da Etiópia, a totalidade do continente ficou de uma forma ou de outra, sob os interesses econômicos e políticos do imperialista ocidental. Não sem motivo, a África passou a ser conhecida como o continente colonial por excelência.

Com as imagens elaboradas pelo mercantilismo e pelo capitalismo industrial no pósguerra, no contexto da independência dos países do continente africano, propagou-se uma nova leitura desqualificante da África. Atualmente, o continente continua dominado pela 
pobreza, pelo subdesenvolvimento, pelas doenças, pelas guerras entre os grupos sociais ali viventes, pelos golpes de Estado contínuos, pelo analfabetismo, pelos refugiados da seca e da falta de perspectivas. Em um mundo desigualmente unificado pela globalização, como todas as desprezadas regiões meridionais do planeta, a África ainda integra a periferia de flagelos sociais.

Nesta nova elaboração plena de estereotipias negativas, o futuro não reservaria nenhuma benesse para o continente, condenado, a priori, à estagnação. Tal como leituras anteriores, essa nova coleção de imagens associa-se a um ideológico, pelo qual a África seria incapaz de conduzir o próprio destino. Ela deve, portanto, continuar a apelar para o Ocidente na busca de soluções para os seus problemas. Como nas imagens anteriores, a visão estereotipada sobre a África e seus povos, por meio de um discurso generalizante e excludente, utiliza-se dos preconceitos e das falsas concepções. Objetivamente, essas perspectivas trabalham em prol da confirmação da submissão da África ao mundo ocidental e às suas expectativas econômicas, sociais e políticas.

Como vimos, todas as construções elaboradas sobre a África nunca se distanciaram da ambição de dominá-la e de configurá-la como contraponto de uma Europa que se arrogava um papel dominante. Ademais, para submeter o que quer que seja, é necessária, antes de tudo, a iniciativa de concretizar-se no nível do imaginário, preferivelmente de modo a distorcer a compreensão do outro, habilitando, desse modo, a irrupção de uma ideologia de dominação.

\section{A África na educação básica}

Por que estudar a história e a cultura africana nas escolas brasileiras? Se o Brasil fosse um país sem nenhuma parcela de afro-descendentes negros, não seria surpreendente que os currículos escolares dispensassem estes conteúdos. Mesmo assim, por razões da história da humanidade ou mesmo da história econômica do capitalismo, seria indispensável um conhecimento da história africana. Surpreendente é que o Brasil, sendo um país que tem cerca de metade da sua população e reconhece a sua ancestralidade no continente africano, não tenha o ensino de aspectos da história africana na constituição de seu currículo escolar.

Ao analisar os livros didáticos trabalhados na sala de aula que tratam da História do Brasil, percebemos a existência de textos e figuras racistas ou preconceituosas, visto que ao reproduzirem os valores socialmente dominantes, negligenciam ou sub-representam a população negra brasileira. Uma parte dos livros didáticos, ao inserirem os negros na História Brasil, comete deslizes que os prejudicam. Muito desses materiais disponíveis para o uso do professor restringem a população negra à escravidão, esquecem que os ascendentes negros, antes de chegar ao Brasil para serem escravizados, tinham uma vivência na África, ou seja, o negro já era envolto em um universo cultural que iria se propagar e contribuir, significativamente, na formação da cultura brasileira.

Um dos primeiros conteúdos programados no ensino de história do Brasil é a chegada dos europeus à América a partir do século XV, os quais, ao terem contato com o novo mundo, procuraram explorar a riqueza natural existente na fauna e na flora. Para empreenderem a política de colonização no continente americano, exploraram as populações indígenas que aqui habitavam, submeteram estes povos à escravidão e desrespeitaram sua organização social e suas práticas culturais.

Os portugueses, ao procurarem efetivar a política de colonização na América, trouxeram da África para o Brasil os negros africanos, que não eram tratados como seres humanos, mas como mercadorias a serem comercializadas e destinadas ao trabalho e, 
consequentemente, submetidas à escravidão.

A colonização portuguesa se efetivou após a década de 30 do século XVI. Apressouse em estabelecer o domínio sobre as terras antes que outra nação, movida pela ambição tal como Portugal, o fizesse.

Nesse processo de colonização, durante mais de trezentos anos, as populações africanas se constituíram pilares da mão-de-obra, contribuindo para a organização da sociedade brasileira. O tratamento dado pelos europeus a essas populações foi também pautado no eurocentrismo e etnocentrismo, desrespeitando as múltiplas etnias que constituíam os africanos, a história do continente de origem e as práticas culturais.

Desde o Brasil Colônia, os negros trabalharam em diferentes espaços: nos engenhos, no interior das casas grandes, nas regiões de mineração e nos espaços urbanos das cidades. Eles desempenhavam diversas atividades, tais como: a plantação da cana-de-açúcar ou alguma atividade ligada ao processamento do açúcar, a mineração de ouro e diamantes, o plantio do café e cuidados com a lavoura do "ouro verde" brasileiro, entre outras. Nas cidades, os africanos e os crioulos exerciam diferentes funções: serviam de carregadores, trabalhavam nos serviços domésticos, aprendiam ofícios e se tornavam carpinteiros, alfaiates, barbeiros, sapateiros e vendedores ambulantes e podiam ser, também, escravos da administração pública.

Os afro-brasileiros foram fundamentais na construção da sociedade e na formação do povo brasileiro, juntamente com outras etnias. Eles ajudaram a construir uma sociedade que passou por várias transformações ao longo do século XIX, marcado por diferentes fatos históricos: Independência do Brasil, em 1822; a organização do Estado nacional, que incentivou a política de imigração para o nosso país e, consequentemente, a substituição do trabalho escravo pelo trabalho livre; a difusão da ideologia do branqueamento; a abolição da escravidão, em 1888; e o advento da República em 1889. Estas transformações não garantiram a inclusão dos ex-escravos negros no mundo do trabalho, ao contrário, foram excluídos socialmente.

A liberdade chegou, porém não propiciou às populações negras o acesso aos bens produzidos nesse processo histórico, como terra, moradia e educação, para garantir uma vida digna. Os ex-escravos negros começaram a travar uma nova luta, que era de sobreviver diante de tantas desigualdades sociais e combater o racismo na sociedade brasileira.

Diante desse contexto de adversidade e desigualdade, organizou-se o Movimento Negro ao longo do século XX, para lutar pelos direitos da população negra e combater o racismo. Carneiro (1998, p.56) salienta que, desde 1910, existia no Brasil uma pequena imprensa negra que divulgava os acontecimentos sociais expressivos da comunidade negra. Entre os primeiros periódicos, segundo a autora, estavam o Bandeirante e o Menelik. Somente após 1918, periódicos como esses assumiram uma atitude mais agressiva, passando para a fase de conscientização do negro e denunciando o racismo da sociedade brasileira.

Dentre os movimentos negros organizados no século passado, podemos destacar o surgimento, em 1931, da Frente Negra Brasileira (FNB), como um grande movimento organizado no país; em 1978, o Movimento Unificado contra a Discriminação Racial, que, em 1979 passou a ser denominado como Movimento Negro Unificado; ambos engajados na luta pela plena cidadania da população negra no Brasil.

Outro desafio que se impôs ao povo negro na luta contra o preconceito racial foi o de combater a difusão da ideia de democracia racial em nosso país, ou seja, a teoria de que havia no Brasil um congraçamento racial, o que expressaria relações harmônicas entre as diferentes etnias que deram e dão origem ao povo brasileiro.

Sob tal perspectiva, "[...] os negros não tinham do que reclamar". Vale ressaltar que os movimentos negros ganharam força após o processo de redemocratização do Brasil na 
década de 1980, já que essa década, no Brasil, significou repensar a nação. O negro mais uma vez percebeu a importância desse momento para requerer o reconhecimento de sua participação na constituição do povo brasileiro. "Um marco na história deste período foi a Constituição Federal de 1988, que tornou o crime de racismo inafiançável" (MALERBA, BERTONI, 2001, p. 61- 63).

A luta do Movimento Negro Unificado e de vários grupos defensores da constituição de uma sociedade multicultural pela conscientização de todos os setores sociais demonstra que o racismo não atinge só os negros. Enquanto processos estruturantes e constituintes da formação histórica social brasileira, o racismo está arraigado no imaginário social e atinge negros, brancos e outros grupos étnico-raciais

A luta pela plena cidadania e pelo combate ao racismo e as práticas de discriminação racial não é um problema apenas da população negra, do afro-descendente ou do Movimento Negro. Essa luta é de todos os que defendem o respeito à diversidade étnicoracial, social e econômica e combatem a desigualdade ou exclusão social.

Podemos postular que a Lei 10.639/2003 aponta a necessidade de construção da história do mundo na formação dos docentes. Meneses (2007) argumenta que se trata da (re)construção de uma "outra" história que considere não só a perspectiva eurocêntrica dominante, ampliando as possibilidades de conhecimento inseridos no currículo escolar.

Em nossa perspectiva, não definimos certos conhecimentos como válidos e verdadeiros, enquanto que outros são considerados supérfluos e irrisórios. Cabe à escola a tarefa de pensar possibilidades de acesso às diferentes culturas, não no sentido de incluir em seu calendário datas exclusivas para trabalhá-las, mas no sentido de permitir que os alunos compreendam que há diferenças e semelhanças entre uma cultura e outra. As relações de disputa por posições sociais e conhecimentos são carregadas de interesses particulares inerentes tanto à sua própria cultura quanto às outras. Por isso, é necessário que os alunos conheçam a cultura de outros grupos e a história de sua própria cultura em um processo de interação e alteridade.

Para o entendimento da história econômica, política e cultural do Brasil, é também necessário consultar a história e a cultura africana. Sem estes elementos se constrói uma história parcial, distorcida e promotora de racismos. A razão que justifica a exclusão da História Africana nos diversos currículos nacionais das diversas modalidades e níveis de ensino é o racismo. A exclusão da História Africana é uma dentre as várias demonstrações do racismo em relação à população negra. Ela produz a eliminação simbólica do africano e da história nacional.

Uma das motivações que os pesquisadores e pesquisadoras e os docentes brasileiros devem ter para estudar a história e a cultura africana é a ausência de sistematização e veiculação das informações relacionadas ao continente africano. Serrano e Waldman (2007) afirmam que essa lacuna é evidente tanto na ausência pura e simples de uma visão realista sobre o continente africano quanto em seu desdobramento direto na persistência de uma visão estereotipada e preconceituosa que lhe é impingida.

Não seria demasiado afirmar que a visão distorcida sobre o continente africano e sua população associa-se à exclusão de parcela ponderável da população brasileira do pleno exercício de seus direitos como cidadãos, exclusão que recai de forma marcante sobre os afro-descendentes. As perspectivas excludentes desmerecem um legado extremamente valioso, responsável por inúmeros valores civilizatórios.

\section{Considerações finais}

Apesar de a história e a cultura africana não terem a devida atenção por parte dos 
historiadores brasileiros, que deveriam ter pautado essa discussão como uma das prioridades para compreender a formação de nosso país, a Lei 10.639/2003 determina o que os estudos sobre temas africanistas devem alcançar em nosso país. Nesse sentido, a África, seus povos e suas culturas tornaram-se foco de interesse para os profissionais da educação, os quais necessitam de capacitação para perceber que a constituição da história de um povo perpassa a dimensão do poder e do saber. Estamos diante de confrontos entre distintas experiências históricas, econômicas e culturais, em que o discurso hegemônico hierarquiza e inferioriza o discurso do "outro".

Desse modo, no tocante à realidade brasileira, o estudo da cultura da população africana posiciona-se como uma contribuição direta aos diversos segmentos da população brasileira, sobretudo da população negra. Desde os primórdios da colonização marcada pela discriminação racial, os negros tiveram as suas práticas ancestrais abafadas, marginalizadas e deturpadas, comprometendo, assim, a sua inserção plena no processo social brasileiro.

Essa repressão cultural, camuflada pelo mito da democracia racial, desdobra-se no não reconhecimento dos valores e das práticas sociais de raízes africanas, interiorizadas pelo conjunto da população brasileira, independentemente de sua origem racial.

Os estudos da história e cultura africana articulam a realidade daquele continente com a realidade social brasileira para salientar as identidades formadoras da nossa população, seja esta européia, indígena ou africana. Com isso, constatamos os inúmeros laços que unem o Brasil ao continente africano, tais como as práticas religiosas, da música, da dança, da oralidade, da culinária, do artesanato, das técnicas agrícolas e a linguagem, entre outros.

A Lei 10.639/2003, ao garantir visibilidade ao afro-brasileiro com a finalidade de propiciar a cidadania e a igualdade racial, por meio de práticas educacionais que valorizem o "outro", contribui para romper com o silêncio histórico sobre a cultura e história da população negra brasileira. Nesse sentido, a Lei abre caminho para a construção de uma educação antirracista, que rompe com as normas discursivas centradas no europeu e no ambiente escolar torna-se legítimo falar sobre a exclusão e marginalização de um segmento social.

Mas não é qualquer fala. É uma fala pautada no diálogo étnico-racial no interior da escola, ou seja, pressupõe e considera a existência do "outro", como sujeito ativo e concreto, com quem se fala e de quem se fala. Esse "outro" deverá ter direito à livre expressão do seu "eu". Tudo isso diz respeito ao reconhecimento de nossas identidades como sujeitos singulares em gênero, raça, idade, nível socioeconômico e tantos outros.

$\mathrm{Na}$ busca pela formação de uma população brasileira que reconheça a identidade cultural do "outro" e perceba que essa pode ser parte do seu "eu", é necessário que o professor e a professora, além de terem conhecimentos sobre as diversas culturas formadoras da nação, estejam comprometidos politicamente com a luta contra a discriminação dentro do espaço escolar. O grande desafio é como provocar nos docentes a vontade, a curiosidade por novos conhecimentos? $O$ que fazer para que os professores/professoras e os alunos/alunas compreendam que instituir práticas curriculares que incentivem a alteridade é caminho para construir uma educação menos excludente?

Enfim, ainda há um longo caminho para que o professorado, como categoria, compreenda a importância da sua prática e da ingenuidade de acreditar na neutralidade do seu trabalho, de suas ações e de sua postura. Além de inserir novos conteúdos no currículo escolar, para efetivação da Lei 10.639/2003, é imprescindível questionar e muitas vezes desconstruir os conhecimentos sociais já instituídos nos currículos. 


\section{Referências}

ABRAMOWICZ. Anete. Trabalhando a diferença na educação infantil. São Paulo: Moderna, 2006.

BRASIL, Ministério da Educação. Diretrizes Curriculares Nacionais para a Educação das Relações Étnico-Raciais e para o Ensino de História e Cultura Afro-Brasileira e Africana. Brasília, MEC/Secad, 2004.

BRASIL. Constituição (1988). Constituição da República Federativa do Brasil. Brasília, DF: Senado, 1988.

BRASIL. Instituto Brasileiro de Geografia e Estatística (IBGE). Pesquisas Nacionais por Amostra de Domicílios (PNDA). Disponível em http://www.ibge.gov.br. Acesso em: 22 ago. 2007a.

BRASIL. Lei $n^{o} 10.639$, de 9 de janeiro de 2003. Altera a Lei $n^{\circ} 9.394$, de 20 de dezembro de 1996, que estabelece as diretrizes e bases da educação nacional, para incluir no currículo oficial da rede de ensino a obrigatoriedade da temática "História e Cultura Afro-Brasileira", e dá outras providências. Diário Oficial da União. Brasília, DF, 10 jan. 2003.

BRASIL. Lei $\mathrm{n}^{\circ}$ 9.394, de 20 de dezembro de 1996. Diretrizes e bases da educação nacional. Diário Oficial da União. Brasília, DF, 23 dez. 1996a.

BRASIL. Ministério da Educação. Secretaria de Educação Fundamental. Parâmetros curriculares nacionais: pluralidade cultural, orientação sexual. Brasília, DF / MEC /SEF 1997.

BRASIL. Presidência da República. Programa Nacional de Direitos Humanos. Brasília, DF : Presidência da República; Secretaria de Comunicação Social; Ministério da Justiça, 1996.

CADERNOS CANTO NAGÔ DO ILÊ AIYÊ. In: África ventre fértil do mundo. Salvador: número VI, 1988.

CONCEIÇÃO, Maria Telvira. Rompendo com o silêncio o negro na escola. In: LIMA, Ivan Costa. Os negros e a escola brasileira. Florianópolis - SC: NEN, 1999. (Pensamento negro em educação, $\mathrm{n}^{\circ}$ 6)

COSTA, Marisa Vorraber. Poder, discurso e política cultural: contribuições dos Estudos Culturais ao campo do currículo? In: LOPES, Alice Casimiro; MACEDO. Elizabeth. (Org.). Currículo: debates contemporâneos. São Paulo: Cortez, 2002.

CUNHA JUNIOR, Henrique. A história africana e os elementos básicos para seu ensino. IN: LIMA, Ivan Costa (Org). Negros e currículo. Florianópolis -SC: NEN, 1998. (Pensamento negro em educação, n. 2)

FELIPE, Delton Aparecido. Narrativas para alteridade: o cinema na formação de professores e professoras para o ensino de história e cultural afro-brasileira e africana na educação básica. 152 f. Dissertação (Mestrado em Educação) - Universidade Estadual de Maringá, PR, 2009.

FELIPE, Delton Aparecido, TERUYA, Teresa Kazuko. O Negro no pensamento educacional brasileiro na Primeira República (1889 -1930). Revista HISTEDBR On-line. , v.27, p.112126. Set. 2007.

FELIPE, Delton Aparecido; TERUYA, Teresa Kazuko. História Afro-brasileira: linguagem fílmica enriquece o conhecimento sobre a temática. Revista do Professor. Ano 24; n 95; jul/set. Porto Alegre - RS, 2008.

FERNANDES, José Ricardo Oriá. Ensino de História e diversidade cultural: desafios e possibilidades. Cadernos Cedes, Campinas-SP, vol. 25, n 67, p. 378-388, set/dez, 2005.

FRY, Peter. A persistência da raça: ensaios antropológicos sobre o Brasil e a. África austral. 
Rio de Janeiro: Civilização Brasileira, 2005.

GOMES, Nilma Lino. Descolonizar os currículos: um desafio para as pesquisas que articulem a diversidade étnico-racial e a formação de professores. In Trajetorias e processos de ensinar e aprender: sujeitos, currículos e culturas - XIV ENDIPE; Porto Alegre - RS: Edipucrs, 2008.

LOPES, Véra Neusa. Inclusão étnico-racial: cumprindo a lei, práticas pedagógicas contemplam afro-brasileiros. In: Revista do Professor. Porto Alegre - RS, vol. 19, n⿳0 75, p. 25-30, jul/set, 2003.

MALERBA, Jurandir; BERTONI, Mauro. Nossa gente brasileira. Campinas, SP: Papirus, 2001.

MENESES, Maria Paula G. Os espaços criados pelas palavras - Racismo, etnicidades e encontro colonial. In GOMES, Nilma Lino (Org.) Um olhar além das fronteiras: educação e relações raciais. Belo Horizonte: Autêntica, 2007.

NADAI, Elza. O ensino de história no Brasil: Trajetória e perspectiva. In. Revista Brasileira de História. v. 13. no 25/26, São Paulo, set. 1992. p. 56 -63

PEREIRA, João Baptista Borges. Negro e a identidade racial brasileira. In: Racismo no Brasil. São Paulo: Perirolopolis; ABONG, 2002.

SCHMIDT, Maria Auxiliadora; CAINELLI, Marlene. Ensinar história. São Paulo: Scipione, 2004.

SERRANO, Carlos; WALDMAN, Mauricio. Memórias D’África: a Temática Africana em Sala de Aula. São Paulo: Cortez, 2007.

SILVA, Ana Célia da. Desconstruindo a Discriminação do Negro no Livro Didático. Salvador, BA, EDUFBA, 1998.

SILVA, Maria Palmira da. O anti-racismo no Brasil: considerações sobre o estatuto social baseado na consciência racial. In: Revista Psicologia Política/Sociedade Brasileira de Psicologia Política, v. 1, n. 1, São Paulo, jan./jun.2001, p. 37-38:

Notas:

${ }^{1} \mathrm{O}$ presente artigo trata de um aspecto analisado na dissertação de mestrado intitulada: Narrativas para alteridade: o cinema na formação de professores e professoras para o ensino de história e cultural afrobrasileira e africana na educação básica, defendido por Delton Aparecido Felipe em março de 2009, junto ao programa de Pós-Graduação em Educação da Universidade Estadual de Maringá-PR.

${ }^{2}$ Email: ddelton@gmail.com

${ }^{3}$ Ressaltamos que quando tratamos de cultura afro-brasileira, não podemos perder de vista que a África, além de ser um imenso continente, coabita grupos étnicos com hábitos culturais distintos que se entrelaçam. Por isso, as identidades culturais africanas são complexas e contraditórias. Ao abordar a relação entre a história africana e a história brasileira estamos nos referindo àquelas regiões da África de onde os negros foram capturados e vendidos por meio das guerras fomentadas pelos europeus, entre outros processos. São os grupos de africanos que contribuíram para a formação da população brasileira. Não é nosso objetivo, porém, tratar nesse artigo sobre a especificidade de cada grupo étnico que foram trazidos para o Brasil, tais como: os Bantus, os Nagôs, os Jejes, os Yorubas, os Males, entre outros. 